\title{
Analysis of Factors Influencing True Blood Loss in Navigated Total Knee Replacements
}

\author{
Laghvendu Shekhar ${ }^{1}$, Yogesh Salphale² \\ ${ }^{1}$ Wockhardt Super Speciality Hospital, Nagpur, India \\ ${ }^{2}$ Shushrusha Multispecialty Hospital, Chandrapur, India \\ Email:yosa@aol.in
}

How to cite this paper: Shekhar, L. and Salphale, Y. (2019) Analysis of Factors Influencing True Blood Loss in Navigated Total Knee Replacements. Surgical Science, 10, 59-69.

https://doi.org/10.4236/ss.2019.102008

Received: December 14, 2018

Accepted: February 24, 2019

Published: February 27, 2019

Copyright () 2019 by author(s) and Scientific Research Publishing Inc. This work is licensed under the Creative Commons Attribution International License (CC BY 4.0).

http://creativecommons.org/licenses/by/4.0/

(c) (i) Open Access

\begin{abstract}
Title: Analysis of factors influencing true blood loss in navigated total knee replacements. Objectives: To evaluate true blood loss in total knee replacements and analyze the various factors such as gender, BMI, diagnosis, size of implants, duration of surgery, tourniquet usage etc. on calculated blood loss using formula by Nadler et al. All the cases included have been done using navigation system and no comparison with conventional jig based surgeries has been attempted. Methods: Retrospectively data of primary cemented total knee replacements performed from October 2012 to August 2013 were evaluated. All surgeries were performed using navigation system. The data collected included patient sex, height, weight and preoperative haemoglobin and hematocrit. The patients' postoperative data of haemoglobin, hematocrit and drains were collected. All patients had their $\mathrm{CBC}$ done on $2^{\text {nd }}$ post operative day. Any data on transfusions that patients received were also collected. We also collected data regarding the size of implant used. We calculated true blood based on formula given by Nadler, Hidalgo \& Bloch. We excluded patients whose data were incomplete or who received tranexamic acid. Patients who needed stems (femoral or tibial) were also excluded from this study. Results: The average true calculated blood loss was $959.44 \mathrm{ml}$. BMI did not have any effect on blood loss. But larger size implants were associated with more blood loss. Conclusion: The preoperative haemoglobin is one of the most important factors in determining transfusion following the knee replacement. Male gender and larger implants are associated with more blood loss. BMI, diagnosis of OA or RA, tourniquet usage and time have no significant effect on blood loss. Our calculated blood loss compares favourably with published literature.
\end{abstract}

\section{Keywords}

Navigated, Total Knee Replacements, Blood Loss, Transfusion 


\section{Introduction}

We assessed perioperative blood loss in patients undergoing computer assisted knee replacements. We decided to analyze the effect of various factors like gender, body mass index (BMI), diagnosis, size of implants, tourniquet and surgery time on true blood loss calculated using method of Nadler et al. (1962) [1] and Gross et al. (1983) [2]. Numerous studies have pointed to the fact that there is significant hidden blood loss in knee replacements. Lotke et al. (1991) [3] have earlier reported around $1518 \mathrm{ml}$ of blood loss in conventional knee replacements. Sehat et al. $(2000,2004)$ [4], [5] have also published report of $1498 \mathrm{ml}$ blood loss in conventional knee replacements using hematological criteria rather than drains. The visible blood loss intraoperatively and in drains post operatively does not correlate with true blood loss which may be substantially higher in knee replacements. The hidden loss estimated at 49 percent by Sehat et al. [5] and 38 percent by Prasad et al. [6]. Earlier studies by Chauhan et al. [7] and Kalairajah et al. [8] have eluded to reduced drain output with navigated surgeries. McConnell et al. [9] published a comparative analysis of navigated and conventional knee replacement and stated that navigated TKR has a blood loss of $1137 \mathrm{ml}$ against $1362 \mathrm{ml}$ in conventional TKR based on formula by Nadler et al. [1].

Because of above studies we decided to analyze results based on calculated blood loss because it more closely reflects the blood loss.

\section{Materials and Methods}

Data of primary cemented total knee replacements performed from October to August 2013 were evaluated retrospectively. All the cases were navigated using Brainlabs ${ }^{T M}$ navigation system.

The data collected included patients sex, height (ht), weight (wt) and preoperative haemoglobin $(\mathrm{Hb})$ and hematocrit $(\mathrm{Hct})$. Intravenous fluids were given for $24 \mathrm{hrs}$ post operatively at the rate of $70-100 \mathrm{ml}$ per hr depending on body weight. All patients had their complete blood count $(\mathrm{CBC})$ done on $2^{\text {nd }}$ post operative day. The patients' postoperative data of haemoglobin, hematocrit (from $\mathrm{CBC}$, done on $2^{\text {nd }}$ post operative day) were evaluated and data on drains were also collected. This was utilized to find the change in Hb and Hct. By 48 hours all fluid shifts must have stabilized. Any data on transfusions that patients received were also collected.

We also collected data regarding the size of implant used. We included 75 unilateral surgeries in 53 patients. We excluded patients whose data were incomplete or those who received tranexamic acid. Patients who needed stems (femoral or tibial) were also excluded from this study. We excluded 11 unilateral surgeries because of incomplete data, 3 surgeries because of use of stems on femoral or tibial side. We excluded 2 cases who received tranexamic acid. One of these cases also developed post surgery acute popliteal artery thrombosis which was identified immediately post surgery and removed using fogharty catheter surgically. This was due to atherosclerotic vascular disease rather than trauma. 
Rest of the stay of this patient was uneventful.

We divided the groups into male and females. Data was stratified into those with BMI over 30 and those below it.

We also stratified data into those with size 1.5, 2 and 2.5 (small), and those with size 3, 4 and 5 (large).

\section{Surgical technique}

We used PFC (Depuy ${ }^{T M}$ ) for all the cases. 13 cases had all poly, 45 cases had RP and 17 cases had metal backed implants. All the cases were navigated using Brainlabs ${ }^{T M}$ system. All cases were operated by Dr Laghvendu Shekhar. Tourniquet was used in 63 of cases throughout the procedure except in 12 cases where it was inflated only during cementing. All had medial parapatellar approach. No attempt was made to do a minimally invasive surgery but we believe that arthrotomy was smaller than in our conventional surgeries. Lateral inferior geniculate artery was coagulated in all the cases. Only 15 cases had patella resurfaced. None of the cases had their patella everted. In cases which were done fully under tourniquet it was kept inflated till skin closure.

A single drain was used in all cases. The drain was kept clamped for two hours post surgery and was removed next morning.

Pharmacological thromboprophylaxis was utilized during all cases. 36 cases received Xarelto, 29 cases received Fragmin, 5 cases received Arixtra, 4 cases ecosprin and 1 case received Eliquis.

\section{Measurement of true calculated blood loss}

We calculated patient's blood volume (PBV) based on formula given by Nadler, Hidalgo \& Bloch (1962) [1].

$$
\mathrm{PBV}=k_{1} \times \operatorname{height}^{3}(\mathrm{~m})+k_{2} \times \text { weight }(\mathrm{kg})+k_{3}
$$

where: $k_{1}=0.3669, k_{2}=0.03219, k_{3}=0.6041$ for men;

$k_{1}=0.3561, k_{2}=0.03308, k_{3}=0.1833$ for women.

These values were derived using radio labelled albumin studies which was a non-invasive method for estimation of blood volume accurately [1]. The blood volume change before and after surgery was then calculated using patient's blood volume multiplied by subtracting post surgery hematocrit from presurgery hematocrit and divided by mean hematocrit (Bourke et al., 1974 [10]; Ward et al., 1980 [11]; Gross, 1983 [2])

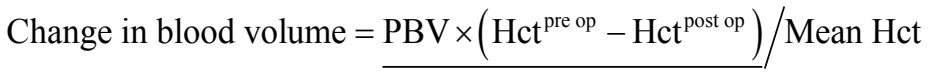

This change in blood volume would represent blood loss if no transfusion was undertaken.

In case patient received blood transfusion before the second post operative hematocrit than this value should be added to the foresaid calculation to calculate the real blood loss in absence of this transfusion [5].

We used a packed red cell concentrate which had a standard $200 \mathrm{ml}$ of RBC volume. Therefore we added 200 multiplied by number of transfusions given. This represented accurately the blood loss [5]. 
This method is more reliable than simply measuring drain output, as it takes account of "hidden" losses [5].

Measuring only the visible blood losses by measuring the drain output and adding the blood losses during surgery grossly underestimates the blood loss [5].

Calculation of the loss of Haemoglobin ( $\mathrm{Hb})$ level was carried out, as a secondary outcome measure, by subtracting the post-operative $\mathrm{Hb}$ from the pre-operative $\mathrm{Hb}$ level and adding the number of units transfused as follows:

Total $\mathrm{Hb}$ loss $=\mathrm{Hb}^{\text {pre op }}-\mathrm{Hb}^{\text {post op }}+$ units transfused

(Assuming 1 unit of blood = $1 \mathrm{~g} / \mathrm{dl}$ ) [1], [12].

\section{Results}

During our study (as shown in Table 1) we had 75 cases, 48 cases were in females and 27 in males.

The mean BMI was $28.22( \pm 5.5)$. The calculated true blood loss was $959.44 \mathrm{ml}$ $( \pm 510.35)$.

Gender

Based on gender (as shown in Table 2) we had 27 cases in males and 48 cases in females. The mean true blood loss in males was $1136.67 \mathrm{ml}( \pm 634.54)$ whereas in females it was $859.75 \mathrm{ml}( \pm 398.94)$. The males had more bleeding as compared to females and this was statistically significant $(\mathrm{P}$ value $=0.047$ ).

Table 1. Showing the various parameters included in our study.

$\begin{array}{cc}\text { Total Patients } & 75 \\ \text { Males } & 27 \\ \text { Females } & 48 \\ \text { Median Age (range) } & 64.89(35-81) \\ \text { Mean Height (SD) in cm } & 157.45( \pm 9.20) \\ \text { Mean weight (SD) in Kg } & 69.73( \pm 13.04) \\ \text { Mean BMI (SD) } & 28.22( \pm 5.5) \\ \text { Mean TQ time (SD) in min } & 75.31( \pm 25.47) \\ \text { Mean surgical time (SD) in min } & 86.67( \pm 9.62) \\ \text { Mean drainage (SD) in ml } & 376.67( \pm 144.61) \\ \text { Estimated True Blood Loss (SD) in ml } & 959.44( \pm 510.35) \\ \text { Mean drop in Hb in gm/dl } & 2.6( \pm 1.12)\end{array}$

Table 2. Gender and blood loss.

\begin{tabular}{|c|c|c|c|c|c|c|}
\hline & Number & $\begin{array}{c}\text { Estimated true } \\
\text { blood loss in } \mathrm{ml}(\mathrm{SD})\end{array}$ & Pre op $\mathrm{Hb}$ in gm/dl & Hemoglobin drop in gm/dl & Transfusions & $\begin{array}{c}\text { Surgery } \\
\text { Time in min }\end{array}$ \\
\hline Male & 27 & $1136.67 \pm 634.54$ & $12.05 \pm 1.44$ & $2.61 \pm .35$ & $0.44 \pm 0.7$ & $85 \pm 7.25$ \\
\hline Female & 48 & $859.75 \pm 398.94$ & $10.96 \pm 1.18$ & $2.6 \pm 0.98$ & $0.96 \pm 0.87$ & $87.6 \pm 10.6$ \\
\hline$P$ value sig if $<0.05$ & & 0.047 & 0.002 & 0.843 & 0.007 & 0.218 \\
\hline
\end{tabular}


Another important factor was that females had significantly lower pre operative $\mathrm{Hb}$ as compared to males. Pre operative $\mathrm{Hb}$ was $10.96 \mathrm{mg} / \mathrm{dl}( \pm 1.18)$ in $\mathrm{fe}$ males vs. $12.05 \mathrm{mg} / \mathrm{dl}( \pm 1.44)$ in males. It was statistically significant. ( $\mathrm{P}$ value $=$ 0.002).

In our study because of their lower preoperative $\mathrm{Hb}$ even though females had less bleeding than males they required more transfusions when compared to males $(\mathrm{P}$ value $=0.007)$. The mean drop in $\mathrm{Hb}$ was almost same in males and females.

\section{Diagnosis}

An analysis of bleeding based on diagnosis (as shown in Table 3 ) that is whether the patient had osteoarthritis (OA) or rheumatoid arthritis (RA), we found that there was no significant difference in bleeding. Rheumatoid patients however had a lower level of pre operative hemoglobin; $10.65 \mathrm{mg} / \mathrm{dl}( \pm 0.58)$ vs. $11.46 \mathrm{mg} / \mathrm{dl}( \pm 1.43)$. This difference was significant $(\mathrm{P}$ value $=0.004)$. There were also more transfusions in RA as compared to OA however it was not significant statistically $(\mathrm{P}$ value $=0.14)$.

\section{Tourniquet}

During our study 63 cases were done with the tourniquet inflated from skin incision to closure where as in 12 cases tourniquet was inflated only during cementing (as shown in Table 4). Although there was more bleeding in cases where tourniquet was inflated only during cementing $[1053.25 \mathrm{ml}( \pm 389.32)$ vs. $941.57 \mathrm{ml}( \pm 530.99)]$. The difference was not found to be statistically significant $(\mathrm{P}$ value $=0.4)$.

\section{Surgery time correlation with calculated blood loss}

When we plotted surgery time against blood loss (as shown in Graph 1) we found that Pearson correlation coefficient was 0.084 . This was clinically not significant $(\mathrm{p}$ value $=0.475$ not significant $)$.

Table 3. Diagnosis and blood loss.

\begin{tabular}{|c|c|c|c|c|c|c|}
\hline & Number & $\begin{array}{l}\text { Estimated true } \\
\text { blood loss in } \mathrm{ml}\end{array}$ & Pre op $\mathrm{Hb}$ in $\mathrm{gm} / \mathrm{dl}$ & $\begin{array}{l}\text { Hemoglobin } \\
\text { drop in gm/dl }\end{array}$ & Transfusions & Surgery time in $\min$ \\
\hline Osteoarthritis & 65 & $970 \pm 521.15$ & $11.46 \pm 1.43$ & $2.5 \pm 1.12$ & $0.69 \pm 0.77$ & $86.03 \pm 8.34$ \\
\hline Rheumatoid Arthritis & 10 & $889.7 \pm 451.55$ & $10.65 \pm 0.58$ & $2.8 \pm 1.17$ & $1.3 \pm 1.16$ & $90.8 \pm 15.63$ \\
\hline$P$ value & & 0.62 & 0.004 & 0.5 & 0.14 & 0.37 \\
\hline
\end{tabular}

Table 4. Tourniquet and blood loss.

\begin{tabular}{ccccccc}
\hline & number & $\begin{array}{c}\text { Estimated true } \\
\text { blood loss }\end{array}$ & Pre op Hb in gm/dl & $\begin{array}{c}\text { Hemoglobin } \\
\text { drop in gm/dl }\end{array}$ & $\begin{array}{c}\text { Transfusions } \\
\text { in unit }\end{array}$ & $\begin{array}{c}\text { Surgery } \\
\text { time in min }\end{array}$ \\
\hline Full tourniquet & 63 & $941.57 \pm 530.99$ & $11.3 \pm 1.35$ & $2.5 \pm 1.12$ & $0.70 \pm 0.78$ & $85.52 \pm 8.82$ \\
Only during cementing & 12 & $1053.25 \pm 389.32$ & $11.63 \pm 1.56$ & $2.8 \pm 1.12$ & $1.17 \pm 1.11$ & $92.67 \pm 11.7$ \\
P value & & 0.40 & 0.49 & 0.41 & 0.19 & 0.07 \\
\hline
\end{tabular}




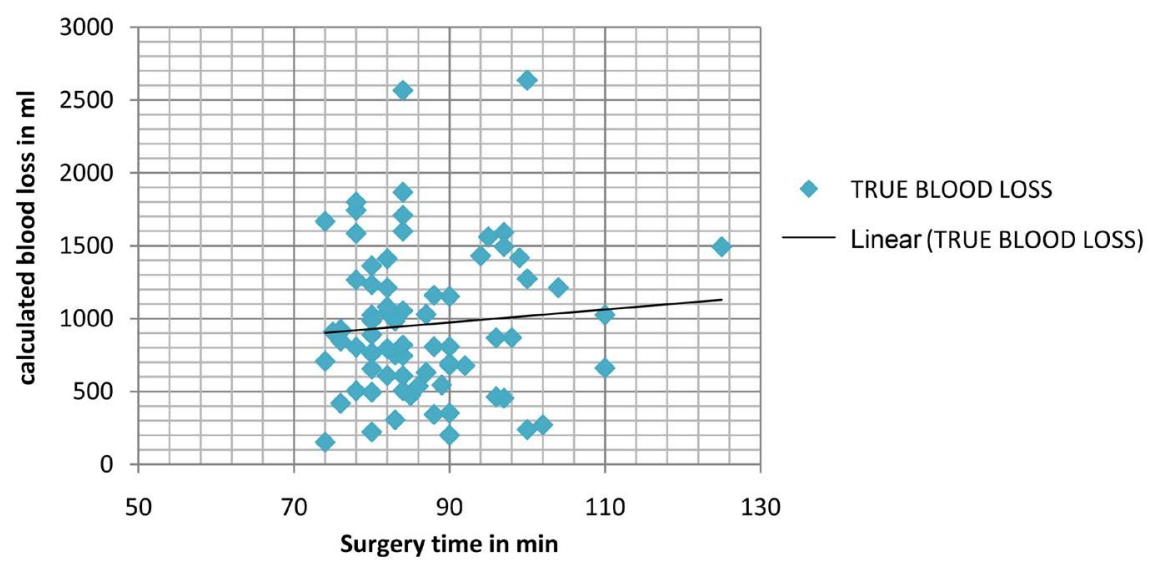

Graph 1. Surgery time correlation with calculated blood loss. Pearson correlation coefficient $=0.084 ; \mathrm{p}$ value $=0.475$ not significant .

\section{BMI}

We divided the cases into two groups (as shown in Table 5). Patients with $\mathrm{BMI} \leq 30$ and patients with BMI $>30$. Fifty patients had BMI less than or equal to 30 whereas 25 patients had BMI more than 30 . We found that there was no difference statistically between the two groups and $\mathrm{P}$ value was not significant $(\mathrm{P}$ value $=0.33)$.

\section{Size of femoral Implant with blood loss}

We also evaluated if size of femoral component had any effect on blood loss (as shown in Table 6). Patient where femoral sizes 1.5, 2, 2.5 (smaller sizes) were implanted were placed in one group which had 43 cases and patients where sizes 3,4 , and 5 (larger sizes) were implanted were placed in second group which had 32 cases. We found that patients with larger size implants bled more than the patients with size $1.5,2$ and $2.5(1159.84 \mathrm{ml} \pm 589.52$ versus $810 \mathrm{ml} \pm 386.02)$. This difference was statistically significant ( $\mathrm{P}$ value 0.005$)$. Here the pre operative $\mathrm{Hb}$ in larger implant size group $(11.72 \pm 1.47)$ was more than that in smaller size group $(11.07 \pm 1.25)$. This value was statistically significant $(\mathrm{P}$ value $=$ 0.049). This could be a pointer to the fact that more males received larger size implants.

\section{Effect of patellar resurfacing}

Patella was resurfaced in 15 cases. The true blood loss was $1151.8 \mathrm{ml} \pm 600.37$.

In majority of cases i.e. 60 cases patella was not resurfaced. The true blood loss was $916.8 \mathrm{ml} \pm 483.83$. Although patella resurfacing group had more blood loss but difference was not statistically significant. ( $P$ value $=0.176)$.

\section{Effect of thromboprophylaxis}

Mean blood loss in $\mathrm{X}$ arel to group was $993.8 \mathrm{ml} \pm 571.93$ which was slightly more than mean blood loss in Fragmin group (878.28 $\mathrm{ml} \pm 382.16)$. But this increased bleeding with $\mathrm{x}$ arel to was not significant $(\mathrm{P}$ value $=0.335)$.

\section{Pre op HB and transfusions correlation}

We plotted blood transfusions and pre operative haemoglobin (as shown in Graph 2). We calculated pears on correlation coefficient which was -0.393 
Table 5. BMI and blood loss.

\begin{tabular}{ccccccc}
\hline & Number & Estimated true blood loss & Pre op Hb & Hemoglobin drop & Transfusions & Surgery time in min \\
\hline $\mathrm{BMI} \leq 30$ & 50 & $996.42 \pm 553.4$ & $11.31 \pm 1.32$ & $2.7 \pm 1.15$ & $0.76 \pm 0.85$ & $86.2 \pm 9.46$ \\
$\mathrm{BMI}>30$ & 25 & $885.48 \pm 411.40$ & $11.43 \pm 1.51$ & $2.4 \pm 1.05$ & $0.8 \pm 0.87$ & $87.6 \pm 10.05$ \\
P value & & 0.33 & 0.75 & 0.26 & 0.85 & 0.57 \\
\hline
\end{tabular}

Table 6. Implant size and blood loss.

\begin{tabular}{|c|c|c|c|c|c|c|}
\hline & Number & Estimated true blood loss in $\mathrm{ml}$ & Pre op $\mathrm{Hb}$ & Hemoglobin drop in gm/dl & Transfusions & Surgery time \\
\hline Sizes $1.5,2,2.5$ & 43 & $810 \pm 386.02$ & $11.07 \pm 1.25$ & $2.47 \pm 1.02$ & $0.88 \pm 0.91$ & $88.19 \pm 10.73$ \\
\hline Sizes $3,4,5$ & 32 & $1159.84 \pm 589.52$ & $11.72 \pm 1.47$ & $2.71 \pm 1.24$ & $0.63 \pm 0.75$ & $84.63 \pm 7.58$ \\
\hline$P$ value & & 0.005 & 0.049 & 0.381 & 0.181 & 0.096 \\
\hline
\end{tabular}

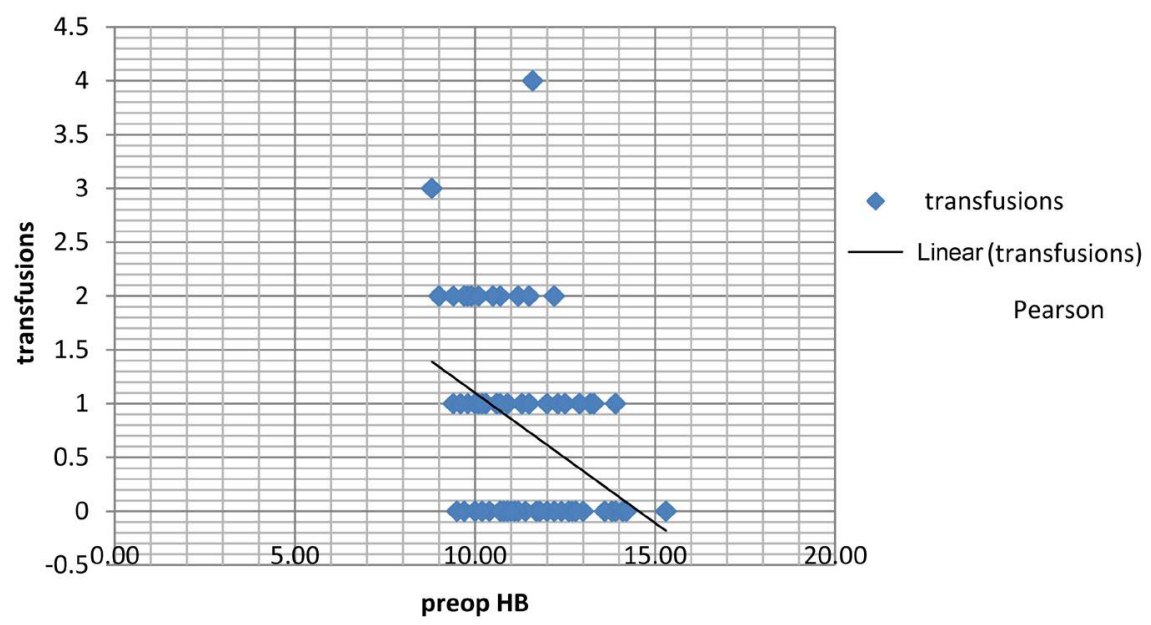

Graph 2. Pearson correlation coefficient -0.393 . P value $<0.01$.

( $\mathrm{p}$ value $=0.01)$. This meant that pre operative haemoglobin was inversely related to blood transfusions and this inverse relationship was significant. Higher the pre operative haemoglobin lower the chance of blood transfusions. Because most of the patients received transfusions in operation theatre itself the percentage of patients having transfusions was very high. Transfusions were given in 42 out of 75 cases. 33 cases had no transfusions, 29 cases had 1 unit, 11 cases had 2 units, 1 case had 3 units and 1 case had 4 units.

If we had strictly followed $8 \mathrm{~g} / \mathrm{dl}$ as cut off for transfusions in 24 cases out of 42 cases transfusions would not have taken place. This would have brought down the transfusion percentage to $23 \%$.

\section{Discussion}

\section{1) Gender}

Cushner and Friedman (1991) [13] found that based on gender there was more blood loss in males as compared to females. Females had more transfusions and they also had lower pre operative haemoglobin levels. 
In paper by Prasad et al. (2007) [6] they found that based on gender there was more blood loss in males as compared to females. Females had lower preoperative $\mathrm{Hb}$ which was not statistically significant. Males also had more transfusions which was not statistically significant.

In our study also males had more blood loss which is in confirmation with both above papers. In our series females had more transfusions which was in confirmation with Cushner and Friedman [13] as well as Francisco Mesa-Ramos et al. (2008) [14] but contrary to findings by Prasad et al. [6]. In both these series as well as our study females had lower preoperative levels as compared to males.

\section{2) Diagnosis}

In our study as well as those by Prasad et al. [6] and Cushner and Friedman [13] there was no significant difference in bleeding in OA or RA groups. In both the studies RA required more transfusions. In both our studies rheumatoid patients had lower pre operative haemoglobin.

\section{3) Tourniquet usage}

As regards tourniquet usage there are number of different reports. Vandenbussche et al. (2002) [15] have published a paper analyzing tourniquet usage. 40 patients were operated under tourniquet and $40 \mathrm{pt}$ without tourniquet. Total calculated blood loss was significantly increased $(P=0.0165)$ without the use of a tourniquet. There was no significant difference in measured blood loss or operating time. The median units of blood given were similar in both groups. Tetro et al. (2001) [16] on the other end reported lower calculated blood loss in the non tourniquet group $(\mathrm{P}$ value $=0.02)$ although tourniquet group had lower visible blood loss indicating tourniquet increases hidden blood loss. During our study 63 cases were done with the tourniquet inflated from skin incision to closure where as in 12 cases tourniquet was inflated only during cementing.

Although we did no surgery without tourniquet the average tourniquet time in patients operated with tourniquet inflated only during cementing was only $21.67 \pm 13.76$ minutes. Although there was more calculated blood loss in cases where tourniquet was inflated only during cementing [1053.25 $\mathrm{ml} \pm 389.32$ vs. $941.57 \mathrm{ml} \pm 530.99]$. The difference was not found to be statistically significant $(\mathrm{P}$ value $=0.4)$ in our study. A larger number of cases can better clear the picture.

\section{4) Surgical time}

We plotted the surgical time against calculated blood loss. We calculated Pearson correlation coefficient and $\mathrm{p}$ value (Pearson correlation coefficient value 0.084 and $\mathrm{P}$ value $=0.475)$. There was a very weak correlation which was not significant in our study. Cushner and Friedman [13] also showed no relation between blood loss and tourniquet or surgery time.

Prasad et al. [6] also reported on intraoperative blood loss, post operative blood loss as well as on apparent total blood loss (intraoperative + post operative) and its correlation with tourniquet time and surgical time. In their paper tourniquet was deflated post cementing, hemostasis achieved and closure was done with tourniquet deflated. 
Prasad et al. [6] reported positive correlation between apparent total blood loss (intraoperative + post operative) against tourniquet time ( $\mathrm{p}$ value $=0.001$ ) and total surgical time $(\mathrm{p}$ value $=0.006$ ). However they did not report on calculated blood loss and tourniquet time or surgical time. Harvey et al. (1997) [17] also reported that longer operations had a greater loss and blood loss was significantly related to tourniquet time $(P=0.0001)$. Our study was in confirmation with Cushner and Friedman [13] but contrary to results by Harvey et al. [17] and Prasad et al. [6].

\section{5) Mean pre-operative $\mathrm{Hb}$ and drop of $\mathrm{Hb}$}

The mean pre operative $\mathrm{Hb}$ in Prasad et al. [6] series was $11.9 \mathrm{mg} / \mathrm{dl}$ and drop of $\mathrm{Hb}$ was $2.53 \mathrm{mg} / \mathrm{dl}$ in males and $2.35 \mathrm{mg} / \mathrm{dl}$ in females. On the other hand Kalarajaiah et al. [8] in their study using non cemented implant stated that mean drop of $\mathrm{Hb}$ was $3.65 \mathrm{mg} / \mathrm{dl}$ in computer assisted surgeries and $5.26 \mathrm{mg} / \mathrm{dl}$ in conventional surgeries. In our series the mean preoperative $\mathrm{Hb}$ was 11.35 $( \pm 1.38) \mathrm{mg} / \mathrm{dl}$. The mean drop in Hb was $2.6( \pm 1.12) \mathrm{mg} / \mathrm{dl}$. This was lower than most of the studies except by Prasad et al. [6]. The added benefit of clamping the drains for two hours post surgery could also be responsible for lower blood loss in our study. Shen et al. (2005) [18] have published a report on reduced blood loss with 4 hour clamping of drain after knee replacement.

6) $\mathrm{BMI}$

As regards BMI numerous papers such as Prasad et al. [6], McConnell et al. [9], and Sehat et al. [5] have shown that obesity or BMI has no effect on blood loss. McConnell et al. [9] also divided there groups into obese (BMI $\geq 30$ ) and non obese $(\mathrm{BMI}<30)$ and found no difference $(\mathrm{P}$ value $=0.967)$.Our study was in conformity with the above as both groups of patients showed no difference in calculated blood loss.

\section{7) Size of implants}

We found that patients with larger implant sizes had more estimated blood loss which was significant ( $\mathrm{p}$ value 0.005 ). We could not find any published study showing any relation. But a larger implant would need a larger incision and a leave larger bleeding surface.

\section{Factors influencing blood transfusions.}

We also plotted a scatter diagram of pre operative haemoglobin and blood transfusions and found a strong and significant negative correlation (Pearson correlation coefficient $-0.393 \mathrm{P}$ value $<0.01$ ).

Francisco Mesa-Ramos et al. [14] in their study of 121 patients found a statistically significant correlation between preoperative $\mathrm{Hb}$ and need for transfusions. They stated that the best predictor for transfusion risk was pre operative Haemoglobin.

The mean calculated blood loss in our study was $959.44 \mathrm{ml}$. The published results like Sehat et al. [5] (1498 ml), Lotke et al. [3] (1518 ml), Prasad et al. [6] (1073 ml), and McConnell et al. [9] (1362 $\mathrm{ml}$ in conventional; $1137 \mathrm{ml}$ in Navigated) have give higher values. 


\section{Conclusion}

To conclude the most important factor in determining transfusion need post knee replacement is preoperative haemoglobin. Male gender and larger implants are associated with more blood loss. BMI, diagnosis of OA or RA, tourniquet usage and time have no significant effect on blood loss. Our calculated blood loss compares favourably with published literature.

\section{Conflicts of Interest}

The authors declare no conflicts of interest regarding the publication of this paper.

\section{References}

[1] Nadler, S.B., Hidalgo, J.U. and Bloch, T. (1962) Prediction of Blood Volume in Normal Human. Surgery, 51, 224-232.

[2] Gross, J.B. (1983) Estimating Allowable Blood Loss: Corrected for Dilution. Anaesthesiology, 58, 277-280. https://doi.org/10.1097/00000542-198303000-00016

[3] Lotke, P.A., Faralli, V.J., Orenstein, E.M. and Ecker, M.L. (1991) Blood Loss after Total Knee Replacement: Effect of Tourniquet Release and Continuous Passive Motion. Journal of Bone and Joint Surgery, 73-A, 1037-1040. https://doi.org/10.2106/00004623-199173070-00011

[4] Sehat, K.R., Evans, R. and Newman, J.H. (2000) How Much Blood Is Really Lost in Total Knee Arthroplasty? Correct Blood Loss Management Should Take Hidden Loss into Account. Knee, 7, 151-155. https://doi.org/10.1016/S0968-0160(00)00047-8

[5] Sehat, K.R., Evans, R.L. and Newman, J.H. (2004) Hidden Blood Loss Following Hip and Knee Arthroplasty. Correct Management of Blood Loss Should Take Hidden Loss into Account. Journal of Bone and Joint Surgery, 86-B, 561-565. https://doi.org/10.1302/0301-620X.86B4.14508

[6] Prasad, N., Padmanabhan, V. and Mullaji, A. (2007) Blood Loss in Total Knee Arthroplasty: An Analysis of Risk Factors. International Orthopaedics, 31, 39-44. https://doi.org/10.1007/s00264-006-0096-9

[7] Chauhan, S.K., Scott, R.G., Breidahl, W. and Beaver, R.J. (2004) Computer-Assisted Knee Arthroplasty versus A Conventional Jig-Based Technique. A Randomised, Prospective Trial. Journal of Bone and Joint Surgery, 86-B, 372-377. https://doi.org/10.1302/0301-620X.86B3.14643

[8] Kalairajah, Y., Simpson, D., Cossey, A.J., Verrall, G.M. and Spriggins, A.J. (2004) Blood Loss after Total Knee Replacement: Effects of Computer-Assisted Surgery. Journal of Bone and Joint Surgery, 87-B, 1480-1482. https://doi.org/10.1302/0301-620X.87B11.16474

[9] McConnell, J., Dillon, J., Kinninmonth, A., Sarungi, M. and Picard, F. (2012) Blood Loss Following Total Knee Replacement Is Reduced When Using Computer-Assisted versus Standard Methods. Acta Orthopaedica Belgica, 78, 75-79.

[10] Bourke, D.L. and Smith, T.C. (1974) Estimating Allowable Haemodilution. Anaesthesiology, 41, 609-612. https://doi.org/10.1097/00000542-197412000-00015

[11] Ward, C.F., Meathe, E.A., Benumof, J.L. and Trousdale, F. (1980) A Computer Nomogram for Blood Loss Replacement. Anaesthesiology, 53, S126. https://doi.org/10.1097/00000542-198009001-00126 
[12] Brecher, M.E., Monk, T. and Goodnough, L. (1997) A Standardized Method for Calculating Blood Loss. Transfusion, 37, 1070-1074. https://doi.org/10.1046/j.1537-2995.1997.371098016448.x

[13] Cushner, F.D. and Friedman, R.J. (1991) Blood Loss in Total Knee Arthroplasty. Clinical Orthopaedics and Related Research, 269, 98-101. https://doi.org/10.1097/00003086-199108000-00015

[14] Mesa-Ramos, F.., Mesa-Ramos, M., Maquieira-Canosa, C. and Carpintero, P. (2008) Predictors for Blood Transfusion Following Total Knee Arthroplasty: A Prospective Randomised Study. Acta Orthopædica Belgica, 74, 83-89.

[15] Vandenbussche, E., Duranthon, L.D., Couturier, M., Pidhorz, L. and Augereau, B. (2002) The Effect of Tourniquet Use in Total Knee Arthroplasty. International Orthopaedics, 26, 306-309. https://doi.org/10.1007/s00264-002-0360-6

[16] Tetro, A.M. and Rudan, J.F. (2001) The Effects of a Pneumatic Tourniquet on Blood Loss in Total Knee Arthroplasty. Canadian Journal of Surgery, 44, 33-38.

[17] Harvey, E.J., Leclerc, J., Brooks, C.E. and Burke, D.L. (1997) Effect of Tourniquet Use on Blood Loss and Incidence of Deep Vein Thrombosis in Total Knee Arthroplasty. Journal of Arthroplasty, 12, 291-296. https://doi.org/10.1016/S0883-5403(97)90025-5

[18] Shen, P.-C., Jou, I.-M., Lin, Y.-T., et al. (2005) Comparison between 4-Hour Clamping Drainage and Nonclamping Drainage after Total Knee Arthroplasty. Journal of Arthroplasty, 20, 909-913. https://doi.org/10.1016/j.arth.2005.01.017 